\title{
A Comprehensive VSM Control Strategy Designed for Unbalanced Grids
}

\author{
Huiyu Miao ${ }^{1}$, Fei Mei ${ }^{2}{ }^{\circledR}$, Yun Yang ${ }^{1}$, Hongfei Chen ${ }^{1}$ and Jianyong Zheng ${ }^{1, *}$ \\ 1 School of Electrical Engineering, Southeast University, Nanjing 210096, China; mhy_seu@163.com (H.M.); \\ mhy034@163.com (Y.Y.); 15651977668@163.com (H.C.) \\ 2 College of Energy and Electrical Engineering, Hohai University, Nanjing 210098, China; meifei@hhu.edu.cn \\ * Correspondence: zhengjy_seu@163.com
}

Received: 7 March 2019; Accepted: 18 March 2019; Published: 26 March 2019

check for updates

\begin{abstract}
A virtual synchronous machine (VSM) is a converter which, compared to other types of converters, has more friendly interactions with the power grid because it is able to simulate the external characteristics of a synchronous machine, which can provide virtual inertia and damping. When the grid voltage is unbalanced, there will be negative sequence current and power oscillations. There will also be double-frequency ripples on the DC bus, which affect the normal operation of the DC power source or load. In order to solve these problems, a comprehensive control strategy is proposed in this paper. The principle of a VSM operated as a current source converter, also called VISMA, is used in the design. A complex coefficient filter is applied to separate the positive and negative sequence components of the grid voltage. By analyzing the reasons of power oscillations under unbalanced voltage, the electrical simulation part of the VSM is improved to achieve several objectives: to suppress negative sequence current and DC voltage ripples. Additionally, the rated voltage in the reactive control part is adaptively adjusted to stabilize the system. The validity of the proposed control strategy is verified by simulation and experiment.
\end{abstract}

Keywords: VSM; three-phase unbalanced; negative sequence; voltage ripple

\section{Introduction}

With the development of the power grid, power electronics is widely applied in the system [1,2]. However, when the proportion of generators or loads interfaced by switched power converters reaches a high level, their impact on the stability and robustness of the power grid cannot be ignored [3]. The power electronic converters, as a common interface, do not have damping and inertia. The power system is more susceptible to power fluctuations and system failures. In order to ensure the reliability and security of the power system, the control strategy of the converters needs to be improved [4-6].

Virtual synchronous machines (VSMs) have been introduced to create a more friendly interaction between converters and the power grid [7]. The concept of VSM is built on the model of the traditional synchronous machine. VSM can be applied in a rectifier and an inverter, which emulates the steady state and transient behavior of the synchronous motor and generator [8]. In this way, the total inertia of the grid is increased. At present, the scientific literature proposes various VSM control models. IEEE Task Force first proposed the static synchronous generator in 1997 [9]. H. P. Beck and R. Hesse proposed the virtual synchronous machine, VISMA, in 2007, which simulates the dynamic and static characteristics of a synchronous machine [10]. In this control algorithm, the stator current is calculated by the stator open-loop equation. A virtual synchronous machine model has been proposed to simulate the generator first-order droop characteristic curve and dynamic mechanical equation in European project "VSYNC" [11]. The synchronverter has been proposed by Q. Zhong et al., which is able to simulate the electromagnetic characteristic, rotor inertia, frequency, and voltage modulation 
characteristic with a second-order model of the synchronous machine [12]. In 2012, generator emulation control (GEC) has been applied in photovoltaics [13].

The above types of VSM are designed for a balanced grid. In reality, due to faults, load imbalances, and other reasons, the grid voltage may appear unbalanced. There are fluctuations in the active and reactive power. For rectifier load, the DC bus voltage also fluctuates at double line frequency, which will affect the current consumption by introducing harmonics.

In a traditional control strategy, the simplest algorithm is to calculate the power reference by decoupling of positive and negative sequence, and then to achieve different control objectives. Some reference also uses current prediction to realize three-phase unbalanced control.

With the difference between VSM and traditional converter control strategy, the unbalanced control strategy cannot be directly used in VSMs. There is already relevant research on the three-phase unbalanced control of VSMs. A multiobjective self-synchronized VSM strategy in unbalanced power grid was proposed in [14], with a second-order generalized integrator applied to deal with the double-frequency ripple. In [15], a cascaded control framework and comprehensive control strategy were proposed, which can flexibly meet the different operational demands. In [16], an improved control strategy based on a double decoupled synchronous reference frame was proposed to compensate the negative current sequence. A hierarchical scheme was proposed to compensate for the voltage imbalance in [17]. However, the current negative sequence and power oscillations were not considered in this reference.

In this paper, a novel three-phase unbalanced control strategy is introduced based on the VSM model VISMA. The three-phase unbalanced operation of a rectifier is analyzed in the paper, as the voltage ripples are more obvious on the DC bus. The control strategy can be applied in an inverter as well. A complex coefficient filter is analyzed and used for positive and negative sequence separation. The electrical simulation part in VISMA is improved to suppress the current negative sequence and the DC voltage ripples. The rated voltage in the reactive control part is also adaptively adjusted. Finally, simulation and experimental results prove the correctness and validity of the proposed control strategy.

\section{Principle and Control of VSMs}

Figure 1 shows the topology of the three-phase rectifier. $R_{d c}$ is the load on the DC bus and $U_{d c}$ is the DC bus voltage. The AC side can be modeled as

$$
L \frac{d i_{a b c}}{d t}=u_{a b c}-e_{a b c}-R i_{a b c}
$$

where $i_{a b c}$ is the three-phase current, $e_{a b c}$ is the bridge short-term average voltage, $u_{a b c}$ is the grid voltage, $L$ is the filter inductance, and $R$ is the equivalent resistance of the filter impedance.

The VSM control algorithm is based on the model of the conventional synchronous machine, which contains the mechanical swing equation (the direction of $\omega$ is taken as in a motor) $[18,19]$ :

$$
J \frac{d \omega}{d t}=T_{e}-T_{m}-D_{p}\left(\omega-\omega_{0}\right)
$$

where $J$ is the moment of inertia, $\omega$ and $\omega_{0}$ are the rotor frequency and its setpoint value respectively, $T_{e}$ and $T_{m}$ represent the electrical and mechanical torques, and $D_{p}$ is the frequency droop coefficient plus the viscous damping coefficient.

As shown in Figure 1, the filter impedance can also be equivalent to the synchronous impedance of the synchronous machine. However, it is much better for stability if the filter impedance is increased virtually [20]. 


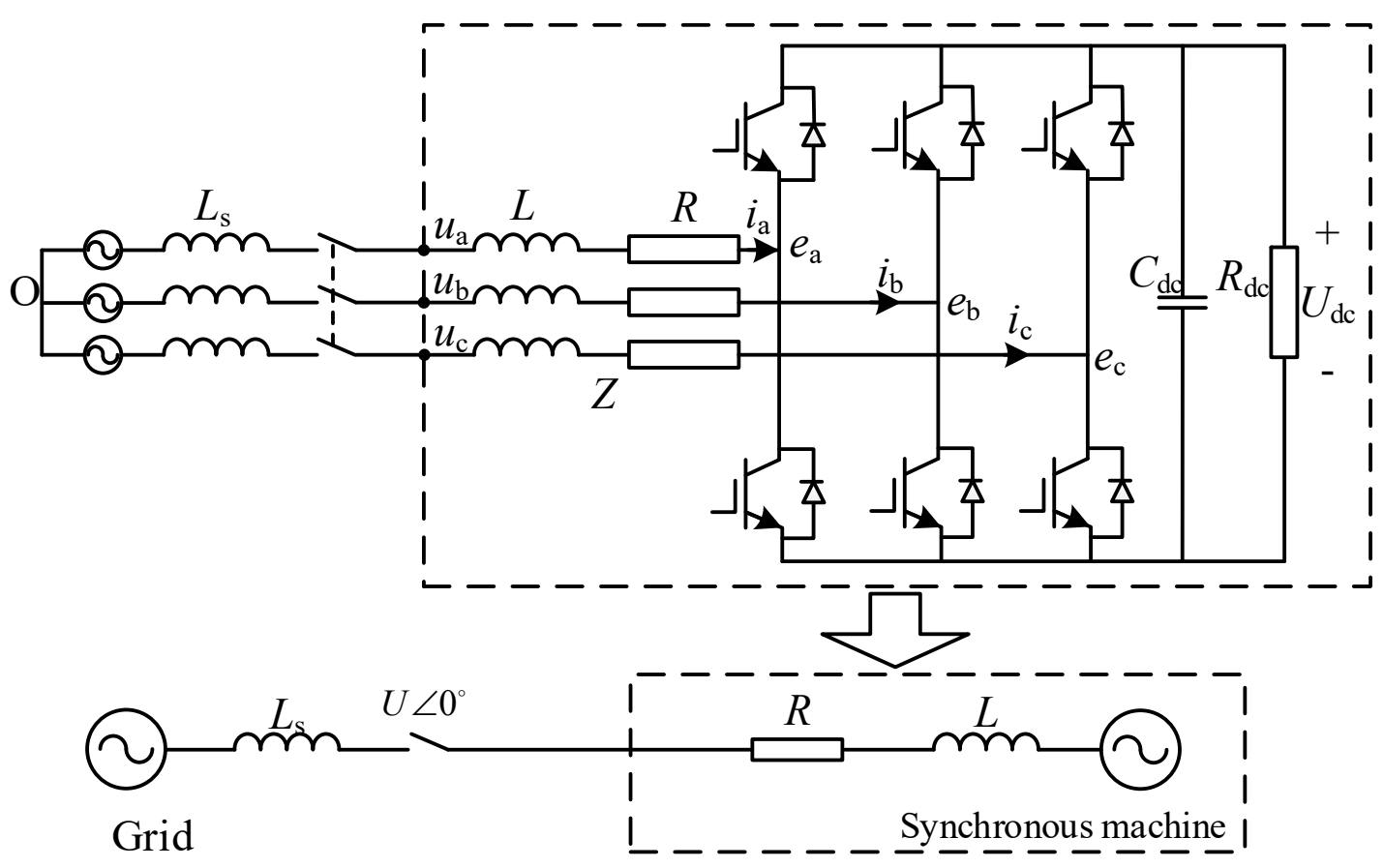

Figure 1. Topology of the three-phase rectifier.

The control diagram of the VSM [21] is shown in Figure 2. $T_{m}$ is determined by the active power control. In this paper, $T_{m}$ is calculated by the DC voltage control block with proportional integral controller to maintain DC voltage stability. $T_{e}$ is calculated by power and frequency. According to (2), the internal frequency is calculated as $\omega$. This is the mechanical equation simulation part.

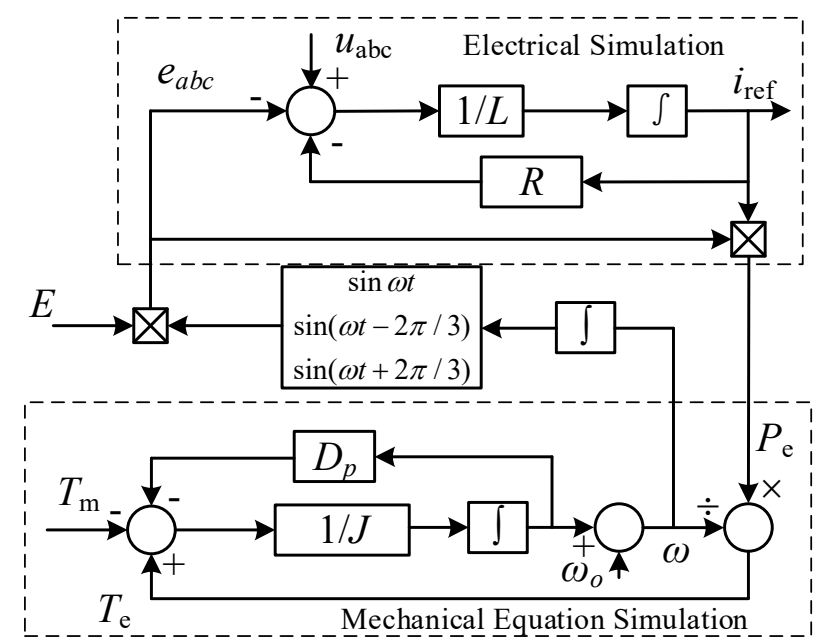

Figure 2. Control diagram of the virtual synchronous machine (VSM).

$E$ is the synchronous internal voltage amplitude, and is composed by

$$
E=E_{0}+k_{q} \cdot\left(Q_{r e f}-Q\right)+k_{v} \cdot\left(U_{r e f}-U\right),
$$

where $E_{0}$ is the rated voltage amplitude, $k_{q}$ is the reactive power adjustment coefficient, $Q_{r e f}$ and $Q$ are the reactive power reference value and actual value, and $U_{r e f}$ and $U$ are the rectifier AC side voltage reference value and actual value, respectively.

The rectifier bridge short-term average voltage is calculated as 


$$
e_{a b c}=\left[\begin{array}{c}
E \sin \omega t \\
E \sin (\omega t-2 \pi / 3) \\
E \sin (\omega t+2 \pi / 3)
\end{array}\right] .
$$

The three-phase current reference $i_{\text {ref }}$ is calculated by the electrical simulation part, which is based on (1), as shown in Figure 2. The pulse width modulation (PWM) control signals are generated in the current inner loop with proportional integral controller or current hysteresis controller.

\section{Analysis of the Unbalanced Grid}

\subsection{Mathematic Model of Unbalanced Voltage}

With the symmetric components method, the three-phase voltage and current can be separated into a positive and negative sequence, as well as zero sequence component. These can be expressed as [22]

$$
\left[\begin{array}{c}
F_{a} \\
F_{b} \\
F_{c}
\end{array}\right]=A^{-1}\left[\begin{array}{c}
F_{+} \\
F_{-} \\
F_{0}
\end{array}\right]=\left[\begin{array}{ccc}
1 & 1 & 1 \\
\alpha^{2} & \alpha & 1 \\
\alpha & \alpha^{2} & 1
\end{array}\right]\left[\begin{array}{c}
F_{+} \\
F_{-} \\
F_{0}
\end{array}\right],
$$

where $F_{a}, F_{b}$ and $F_{c}$ denote the three-phase voltage or current components, $F_{+}, F_{-}$and $F_{0}$ denote the positive, negative, and zero sequence components, and $\alpha$ denotes the twiddle factor, $\alpha=e^{j 2 \pi / 3}$.

The positive, negative, and zero sequence components can also be expressed as

$$
\left[\begin{array}{l}
F_{+} \\
F_{-} \\
F_{0}
\end{array}\right]=A\left[\begin{array}{l}
F_{a} \\
F_{b} \\
F_{c}
\end{array}\right]=\left[\begin{array}{ccc}
1 & \alpha & \alpha^{2} \\
1 & \alpha^{2} & \alpha \\
1 & 1 & 1
\end{array}\right]\left[\begin{array}{c}
F_{a} \\
F_{b} \\
F_{c}
\end{array}\right]
$$

If the three-phase load is unbalanced, the grid voltage can be derived as

$$
\left[\begin{array}{l}
u_{a} \\
u_{b} \\
u_{c}
\end{array}\right]=\left[\begin{array}{lll}
Z_{L a a} & Z_{L a b} & Z_{L a c} \\
Z_{L b a} & Z_{L b b} & Z_{L b c} \\
Z_{L c a} & Z_{L c b} & Z_{L c c}
\end{array}\right]\left[\begin{array}{c}
i_{a} \\
i_{b} \\
i_{c}
\end{array}\right]
$$

where $Z_{L i j}(i, j=a, b, c)$ denotes the load impedance between phase $i$ and phase $j$. With the symmetrical component decomposition method, (6) can be rewritten as

$$
\left[\begin{array}{c}
u_{+} \\
u_{-} \\
u_{0}
\end{array}\right]=\mathbf{Z}_{\mathrm{L}+-0}\left[\begin{array}{c}
i_{+} \\
i_{-} \\
i_{0}
\end{array}\right]=\left[\begin{array}{ccc}
Z_{\mathrm{L}++} & Z_{\mathrm{L}+-} & Z_{\mathrm{L}+0} \\
Z_{\mathrm{L}-+} & Z_{\mathrm{L}--} & Z_{\mathrm{L}-0} \\
\mathrm{Z}_{\mathrm{L} 0+} & Z_{\mathrm{L} 0-} & \mathrm{Z}_{\mathrm{L} 00}
\end{array}\right]\left[\begin{array}{c}
i_{+} \\
i_{-} \\
i_{0}
\end{array}\right],
$$

where $Z_{L m n}(m, n \in\{+,-, 0\})$ denote the coupling impedance between the $m$ and $n$ sequence.

Similarly, the three-phase rectifier modeled in (1) can be expressed as follows:

$$
\left[\begin{array}{c}
e_{+}-u_{+} \\
e_{-}-u_{-}
\end{array}\right]=\left[\begin{array}{cc}
\mathrm{Z}_{\mathrm{G}++} & 0 \\
0 & \mathrm{Z}_{\mathrm{G}--}
\end{array}\right]\left[\begin{array}{c}
i_{+} \\
i_{-}
\end{array}\right]
$$

It can be abbreviated as

$$
E^{+-}-U^{+-}=Z_{G} I^{+-},
$$

where $Z_{G}$ denotes the grid impedance. As a three-phase three-wire system is adopted in the paper, the zero sequence can be neglected.

The VSM control strategy, shown in the Figure 2, does not take the transient potential into account. The impedance in $\mathrm{d}$ and $\mathrm{q}$ axis is set to be the same. Similarly to a synchronous machine, positive sequence $Z_{G++}$ and negative sequence $Z_{G--}$ are equal: 


$$
Z_{G++}=Z_{G--}=Z \text {. }
$$

With the decoupling control of positive and negative sequence, the VSM performance under three-phase unbalanced conditions can be improved. Additionally, the virtual impedance $Z_{V-}$ is introduced in order to change the equivalent impedance of the whole system.

\subsection{Power Oscillation Analysis}

Figure 3 shows the three-phase unbalanced voltage and current in $\alpha, \beta$ static coordinates. $U$ and $I$ are the three-phase grid voltage and current vectors. $U_{+}$and $U_{-}$are the amplitudes of the positive and negative sequence voltage. $I_{+}$and $I_{-}$are the amplitudes of the positive and negative sequence current. $\varphi_{+}(t)$ and $\varphi_{-}(t)$ are the real-time phase angles of the positive and negative sequence voltage components, $\gamma_{+}(t)$ and $\gamma_{-}(t)$ are the real-time phase angles of the positive and negative sequence current components, and $\omega$ is the grid frequency.

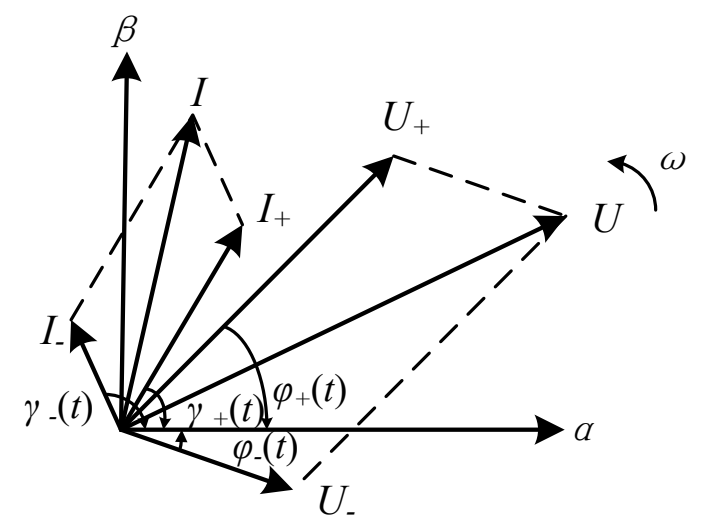

Figure 3. The positive and negative sequence components diagram.

The space vector of the voltage $U$ can be expressed as

$$
\mathbf{U}=U_{+} e^{j \omega t+j \varphi_{+}}+U_{-} e^{-j \omega t+j \varphi_{-}},
$$

where $\varphi_{+}$and $\varphi_{-}$are the initial phases of positive and negative sequence voltage.

The space vector of the current $I$ can be expressed as

$$
\mathbf{I}=I_{+} e^{j \omega t+j \gamma_{+}}+I_{-} e^{-j \omega t+j \gamma_{-}},
$$

where $\gamma_{+}(t)$ and $\gamma_{-}(t)$ are the initial phases of positive and negative sequence current.

The input complex power $S$ can be derived as

$$
\begin{aligned}
2 / 3 \mathbf{S} & =\mathbf{U} \cdot \mathbf{I}^{*} \\
& =U_{+} I_{+} e^{j\left(\varphi_{+}-\gamma_{+}\right)}+U_{-} I_{-} e^{j\left(\varphi_{-}-\gamma_{-}\right)} \\
& +U_{+} I_{-} e^{j 2 \omega_{0} t+j\left(\varphi_{+}-\gamma_{-}\right)}+U_{-} I_{+} e^{-j 2 \omega_{0} t+j\left(\varphi_{-}-\gamma_{+}\right)}
\end{aligned},
$$

and the input active power can be derived as

$$
\begin{aligned}
2 / 3 P & =\operatorname{Re}[2 / 3 \mathbf{S}] \\
& =U_{+} I_{+} \cos \left(\varphi_{+}-\gamma_{+}\right)+U_{-} I_{-} \cos \left(\varphi_{-}-\gamma_{-}\right) \\
& +U_{+} I_{-} \cos \left(2 \omega t+\varphi_{+}-\gamma_{+}\right) \\
& +U_{-} I_{+} \cos \left(-2 \omega t+\varphi_{-}-\gamma_{+}\right)
\end{aligned}
$$

The reactive power can be derived as 


$$
\begin{aligned}
2 / 3 Q & =\operatorname{Im}[2 / 3 \mathbf{S}] \\
& =U_{+} I_{+} \sin \left(\varphi_{+}-\gamma_{+}\right)+U_{-} I_{-} \sin \left(\varphi_{-}-\gamma_{-}\right) \\
& +U_{+} I_{-} \sin \left(2 \omega t+\varphi_{+}-\gamma_{+}\right) \\
& +U_{-} I_{+} \sin \left(-2 \omega t+\varphi_{-}-\gamma_{+}\right)
\end{aligned}
$$

According to (15) and (16), there are double-frequency ripples in the active and reactive power transmission which affect the normal operation of the VSM.

\subsection{Positive and Negative Sequence Separation}

In order to separate the positive and negative sequences, a complex coefficient filter (CCF) was applied in this paper. The unit gain and phase shift are 0 at the selected frequency in an ideal complex coefficient filter. The transfer function of the first-order complex coefficient filter is as follows [23]:

$$
G(s)=\frac{\omega_{\mathcal{c}}}{s-j \omega_{s e t}+\omega_{c}},
$$

where $\omega_{\text {set }}$ is the selected frequency and $\omega_{c}$ is the cutoff frequency.

Figure 4 shows the Bode diagram of the complex component filter. With the increase of $\omega_{\mathcal{c}}$, the waveform is getting flatter and amplitude-frequency characteristics is bigger. The wider the bandwidth, the better the adaptability of the amplitude-frequency characteristics. However, phase deviation is getting greater too.

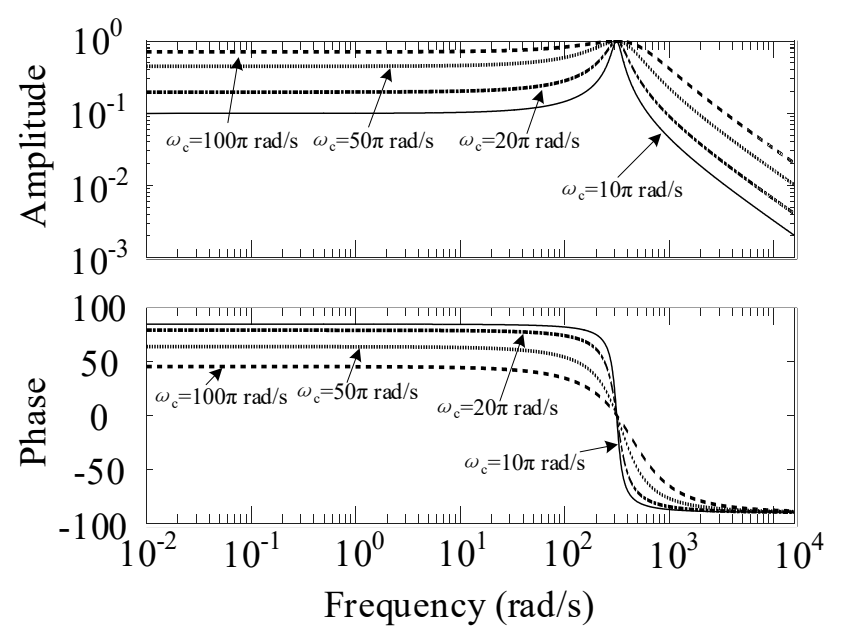

Figure 4. The Bode diagram of the complex component filter $\left(\omega_{\text {set }}=100 \pi \mathrm{rad} / \mathrm{s}\right)$.

Figure 5 shows the implementation diagram for positive sequence separation in a real number field. It can be expressed as

$$
\left\{\begin{array}{l}
F_{\alpha}^{+}=\frac{\omega_{c}}{s-j \omega_{s e t}+\omega_{c}} F_{\alpha} \\
F_{\beta}^{+}=\frac{\omega_{c}}{s-j \omega_{s e t}+\omega_{c}} F_{\beta}
\end{array} .\right.
$$

(18) can be rewritten, as follows, in the time domain:

$$
\left\{\begin{array}{l}
\dot{F}_{\alpha}^{+}=\omega_{\mathrm{c}}\left(F_{\alpha}-F_{\alpha}^{+}\right)-\omega_{\text {set }} F_{\beta}^{+} \\
\dot{F}_{\beta}^{+}=\omega_{\mathrm{c}}\left(F_{\beta}-F_{\beta}^{+}\right)-\omega_{\text {set }} F_{\alpha}^{+}
\end{array} .\right.
$$

The state space representation of the system is

$$
\left\{\begin{array}{l}
\dot{\mathbf{x}}(t)=\mathbf{A}(t) \cdot \mathbf{x}(t)+\mathbf{B}(t) \cdot \mathbf{x}(t) \\
\mathbf{y}(t)=\mathbf{C} \cdot \mathbf{x}(t)
\end{array}\right.
$$


where

$$
\begin{gathered}
\mathbf{A}(t)=\left[\begin{array}{cc}
-\omega_{c} & -\omega_{\mathrm{set}} \\
\omega_{\mathrm{set}} & -\omega_{\mathrm{c}}
\end{array}\right], \\
\mathbf{B}(t)=\left[\begin{array}{cc}
\omega_{\mathrm{c}} & 0 \\
0 & \omega_{\mathrm{c}}
\end{array}\right], \\
\mathbf{C}(t)=\left[\begin{array}{ll}
1 & 0 \\
0 & 1
\end{array}\right], \\
\mathbf{x}(t)=\mathbf{y}(t)=\left[\begin{array}{ll}
F_{\alpha}^{+} & F_{\beta}^{+}
\end{array}\right] .
\end{gathered}
$$

The solution of (20) is

$$
\mathbf{x}(t)=e^{A\left(t-t_{0}\right)} \mathbf{x}\left(t_{0}\right)+\int_{t 0}^{t} e^{A(t-\tau)} \mathbf{B u}(\tau) d \tau .
$$

The steady state solution is

$$
\mathbf{x}(t)=\left[\begin{array}{c}
F^{+} \sin \left(\omega_{\text {set }} t+\theta^{+}\right) \\
-F^{+} \cos \left(\omega_{\text {set }} t+\theta^{+}\right)
\end{array}\right] .
$$

The solution shows positive sequence $F_{\alpha}^{+}$and $F_{\beta}^{+}$in rotating coordinates. According to the theoretical analysis above, the positive and negative sequences can be separated with a complex coefficient filter. In practice, there may be some deviation in the detected frequency, and the transient response performance is also affected by the cutoff frequency $\omega_{c}$.

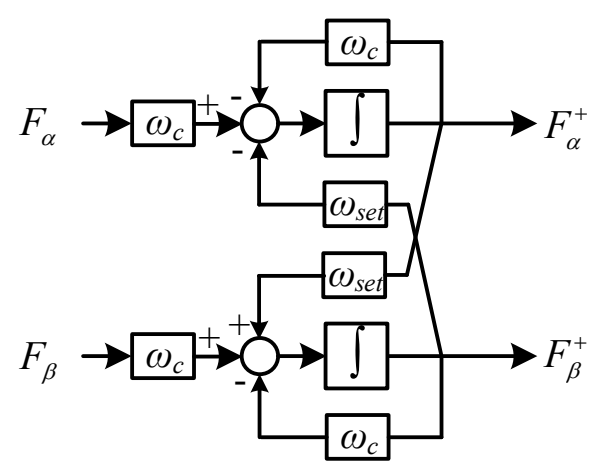

Figure 5. The implementation diagram for positive sequence separation.

\section{VSM Control under Unbalanced Conditions}

\subsection{Suppress the Current Negative Sequence}

Due to the negative sequence current, the grid side current is three-phase unbalanced, which affects the performance of the converter. In order to suppress the negative sequence current, make $I_{-}$ in (13) equal to 0.

The complex power $S$ can be derived as

$$
\begin{aligned}
2 / 3 \mathbf{S} & =\mathbf{U} \cdot \mathbf{I}^{*} \\
& =U_{+} I_{+} e^{j\left(\varphi_{+}-\gamma_{+}\right)}+U_{-} I_{+} e^{-j 2 \omega_{0} t+j\left(\varphi_{-}-\gamma_{+}\right)}
\end{aligned}
$$

With double-frequency components in the active power, there are double-frequency ripples on the DC bus. The negative sequence current can be suppressed by improving the electrical simulation part, as shown in Figure 6. 


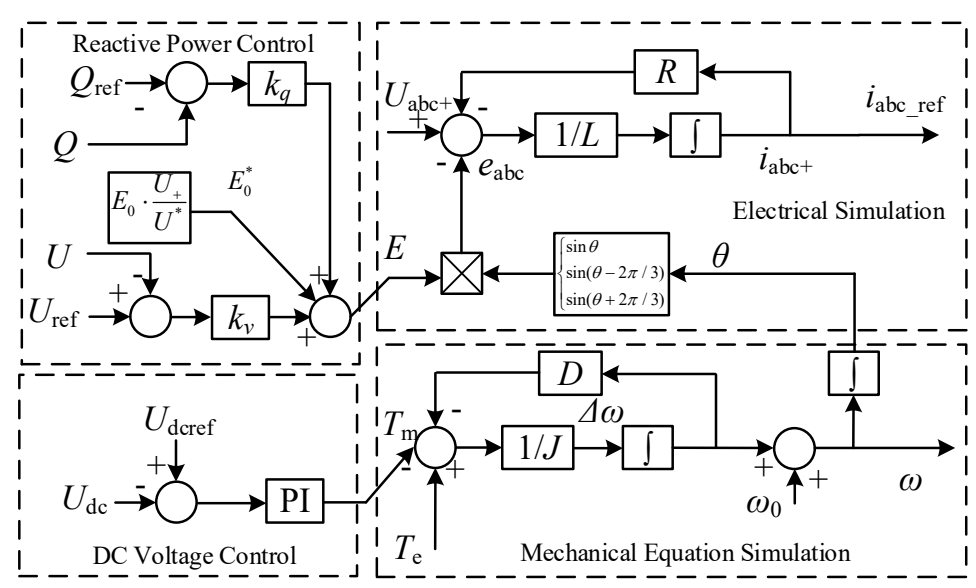

Figure 6. VSM control block diagram with no negative sequence current.

The voltage amplitude decreases from $U$ to $U_{+}$. If the rated voltage in the reactive power control part remains, the initial value will be unchanged, and the reactive power transmission will be affected. The direction of power even reverses when the voltage deviation increases to a certain value. In order to ensure the stable operation of the VSM, $E_{0}$ is adjusted to

$$
E_{0}^{*}=E_{0} \cdot \frac{U_{+}}{U^{*}}
$$

where $U^{*}$ is the grid voltage amplitude under normal operation conditions.

In the electrical simulation part, only positive sequence current is calculated. With current inner control loop, the three-phase current is

$$
i_{a b c}=i_{a b c \_r e f}=i_{a b c+1}
$$

where $i_{a b c+}$ is the positive sequence current.

\subsection{Suppress DC Voltage Ripples}

There are ripples on the DC bus when the grid voltage is three-phase unbalanced, and it affects the normal operation of the DC load. In order to suppress the ripples, a virtual impedance is introduced in the paper.

The transferred active power must be constant to keep the voltage stable on the DC bus, which means the double-frequency components in (14) should equal to 0 , shown as

$$
U_{+} I_{-} \cos \left(2 \omega t+\varphi_{+}-\gamma_{+}\right)+U_{-} I_{+} \cos \left(-2 \omega t+\varphi_{-}-\gamma_{+}\right)=0 \text {. }
$$

Then, (26) can be rewritten as

$$
\left\{\begin{array}{l}
{\left[\varphi_{+}(t)-\gamma_{+}(t)\right]+\left[\varphi_{-}(t)-\gamma_{-}(t)\right]=\pi} \\
\frac{U_{+}}{I_{+}}=\frac{U_{-}}{I_{-}}
\end{array}\right.
$$

When (26) holds, the active power is constant, and the reactive power is

$$
2 / 3 Q=U_{+} I_{+} \sin \left(\varphi_{+}-\gamma_{+}\right)+U_{-} I_{-} \sin \left(\varphi_{-}-\gamma_{-}\right)+2 U_{+} I_{-} \sin \left(2 \omega t+\varphi_{+}-\gamma_{+}\right) .
$$

As can be seen from (28), there are double-frequency components in the reactive power when the active power is constant. 
With a virtual impedance introduced in the virtual electrical simulation part, the current reference can be derived as

$$
\left\{\begin{array}{cl}
I_{+r e f} \cdot\left(R_{v+}+j \omega L_{v+}\right) & =\left[E \cos \left(\theta-\gamma_{+}(t)\right)-U_{+} \cos \left(\varphi_{+}(t)-\gamma_{+}(t)\right)\right] \\
& +j\left[E \sin \left(\theta-\gamma_{+}(t)\right)-U_{+} \sin \left(\varphi_{+}(t)-\gamma_{+}(t)\right)\right] \\
I_{-r e f} \cdot\left(R_{v-}-j \omega L_{v-}\right) & =-U_{-} \cos \left(\varphi_{-}(t)-\gamma_{-}(t)\right)-j U_{-} \sin \left(\varphi_{-}(t)-\gamma_{-}(t)\right)
\end{array}\right\}
$$

where $I_{+r e f}$ and $I_{-r e f}$ denote the positive and sequence reference current, $R_{v+}$ and $L_{v+}$ are the virtual resistance and inductance in the positive network which equal to filter impedance, and $R_{v-}$ and $L_{v-}$ are the virtual resistance and inductance in the negative network.

Substitute (26) into (28),

$$
\begin{aligned}
I_{-r e f} \cdot\left(R_{v-}-j \omega L_{v-}\right) & =U_{-} \cos \left(\varphi_{+}(t)-\gamma_{+}(t)\right)-j U_{-} \sin \left(\varphi_{+}(t)-\gamma_{+}(t)\right) \\
& =\frac{U_{+} I_{-r e f}}{I_{+r e f}} \cos \left(\varphi_{+}(t)-\gamma_{+}(t)\right)-j \frac{U_{+} I_{-r e f}}{I_{+r e f}} \sin \left(\varphi_{+}(t)-\gamma_{+}(t)\right)^{\prime}
\end{aligned}
$$

and the virtual impedance is

$$
\left\{\begin{array}{l}
R_{v-}=\frac{U_{+} \cos \left(\varphi_{+}(t)-\gamma_{+}(t)\right)}{I_{+ \text {ref }}} \\
L_{v-}=\frac{U_{+} \sin \left(\varphi_{+}(t)-\gamma_{+}(t)\right)}{\omega I_{+ \text {ref }}}
\end{array} .\right.
$$

With rated voltage set as (24), the control block diagram is shown as Figure 7. When the three-phase voltage is balanced, the negative sequence reference current is 0 , and the rated voltage is $E_{0}$, which will not affect the normal operation of the VSM.

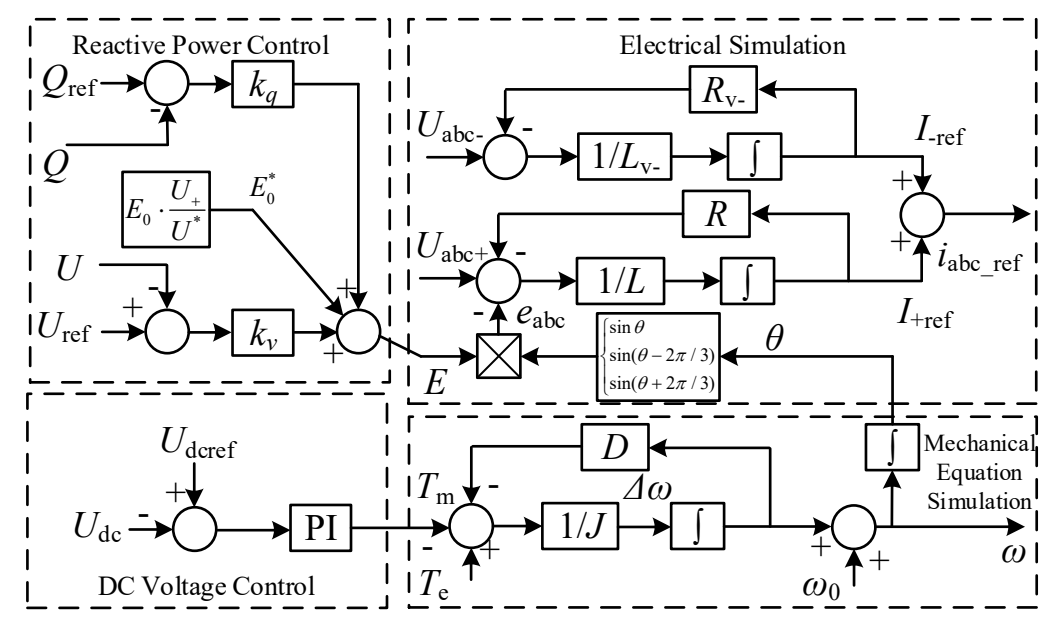

Figure 7. VSM control block diagram with no DC voltage ripples.

\section{Simulation}

In order to verify the correctness and validity of the control strategy, a simulation model was built in MATLAB/Simulink. The main parameters of the simulation are shown in Table 1. The scheme of the modeled system is shown in Figure 8.

Table 1. Simulation parameters.

\begin{tabular}{cccc}
\hline Parameter & Value & Parameter & Value \\
\hline$J /\left(\mathrm{kg} \cdot \mathrm{m}^{2}\right)$ & 0.02 & $Q_{\text {ref }} /$ Var & 0 \\
$D$ & 10 & $E_{0} / \mathrm{V}$ & 311 \\
$\omega_{0} /(\mathrm{rad} / \mathrm{s})$ & $100 \cdot \pi$ & $U_{\text {dcref }} / \mathrm{V}$ & 800 \\
$k_{v}$ & 0.1 & $R / \Omega$ & 0.3 \\
$k_{q}$ & 0.007 & $L / \mathrm{mH}$ & 2 \\
\hline
\end{tabular}




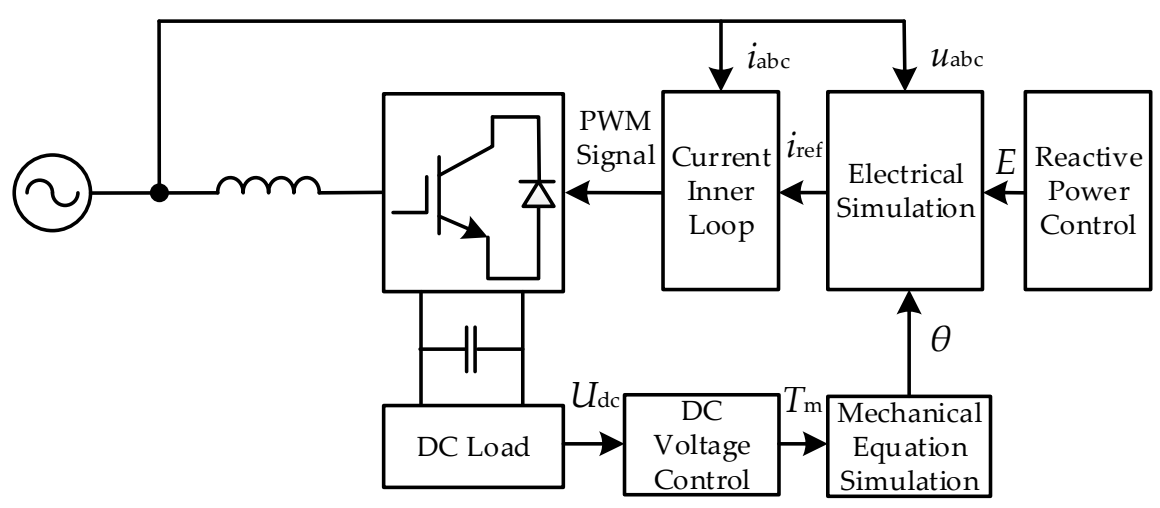

Figure 8. The scheme of the modeled systems.

In the simulation, the effective value of the grid phase voltage was set to $220 \mathrm{~V}$. The DC bus voltage was set to $800 \mathrm{~V}$. The load resistance was set to $100 \Omega$. The DC capacitor was set to $2200 \mu \mathrm{F}$. The filter on the AC side was set to $2 \mathrm{mH}$.

The proportional integral (PI) controller and the current hysteresis controller were applied in the paper. The steady state simulation results were similar. The proportionality coefficient of the PI controller was 10. The integral coefficient was 2 . The hysteresis wide of the current hysteresis controller was $0.1 \mathrm{~A}$. The simulation started recording at $1 \mathrm{~s}$. Initially, the grid frequency was set to $49.8 \mathrm{~Hz}$ and the DC voltage was $800 \mathrm{~V}$. The reactive power reference $Q_{r e f}$ was 0 to obtain the unity power factor for the DC load $100 \Omega$. At $2 \mathrm{~s}$, the grid voltage frequency increased from 49.8 to $50 \mathrm{~Hz}$, and at $3 \mathrm{~s}$, the DC voltage increased from 800 to $900 \mathrm{~V}$. At $4 \mathrm{~s}$, DC resistance decreased from 100 to $50 \Omega$. At $5 \mathrm{~s}$, $Q_{\text {ref }}$ was changed to 100 Var. The simulation results are shown in Figure 9. The VSM rectifier tracked the grid frequency and the DC voltage maintained the reference value.

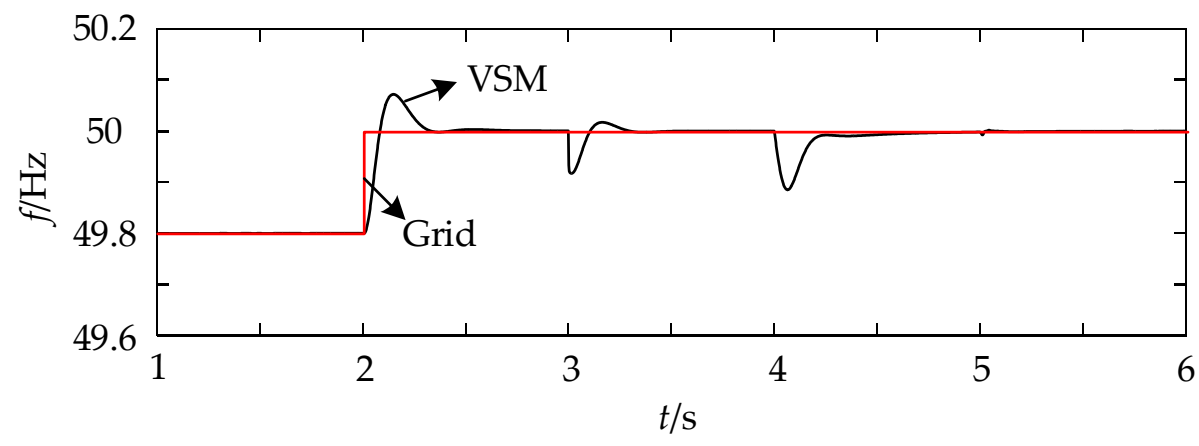

(a) Frequency $(\mathrm{Hz})$

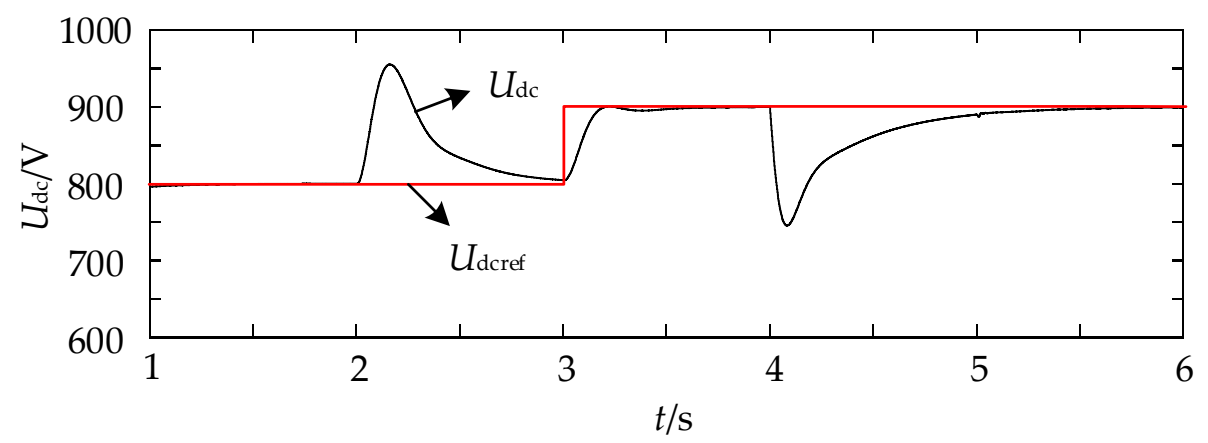

(b) DC bus voltage (V)

Figure 9. Cont. 


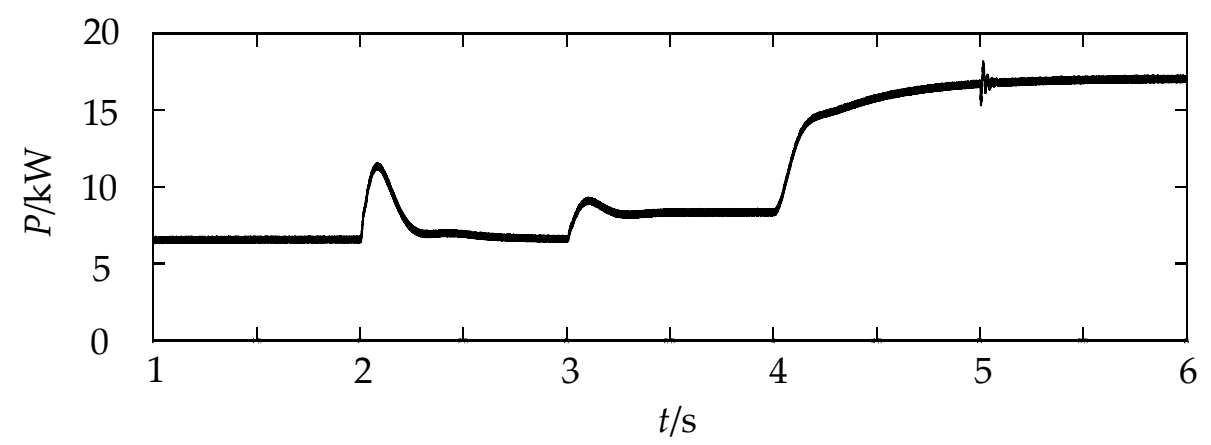

(c) Active load (kW)

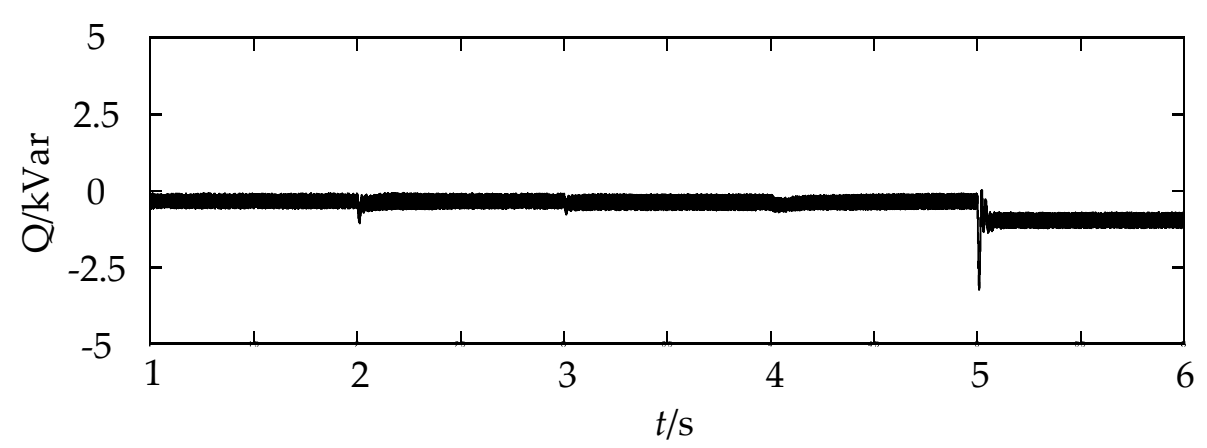

(d) Reactive load (kVar)

Figure 9. Simulation of the VSM under normal conditions.

In order to simulate the grid voltage imbalance, phase A voltage dropped from 220 to $110 \mathrm{~V}$ at $1 \mathrm{~s}$ with a $50 \Omega$ DC load. Figures 10 and 11 show the current and DC voltage with a PI current inner loop. Figures 12 and 13 show the current and DC voltage with a current hysteresis loop. Regardless of whether it was the PI current inner loop or the current hysteresis loop, there were deviations in both phase angle and amplitude of the current at steady state and currents were completely distorted with the current hysteresis loop. There were $\pm 10 \mathrm{~V}$ double-frequency ripples on the DC bus. With the traditional VSM control strategy, the converter could no longer operate stably and safely under three-phase unbalanced conditions.

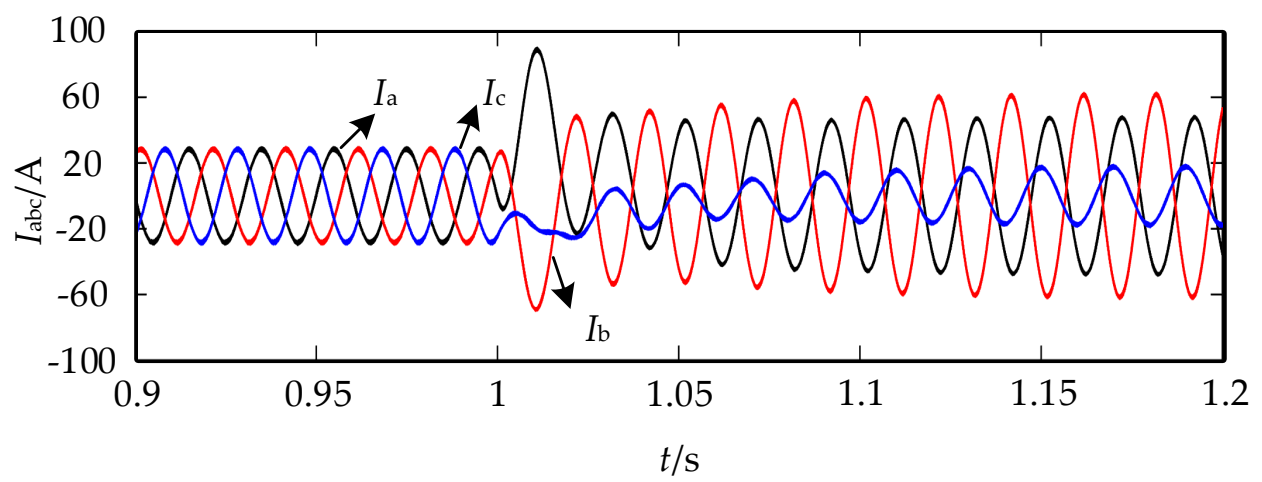

Figure 10. Three-phase currents with a PI current inner loop. 


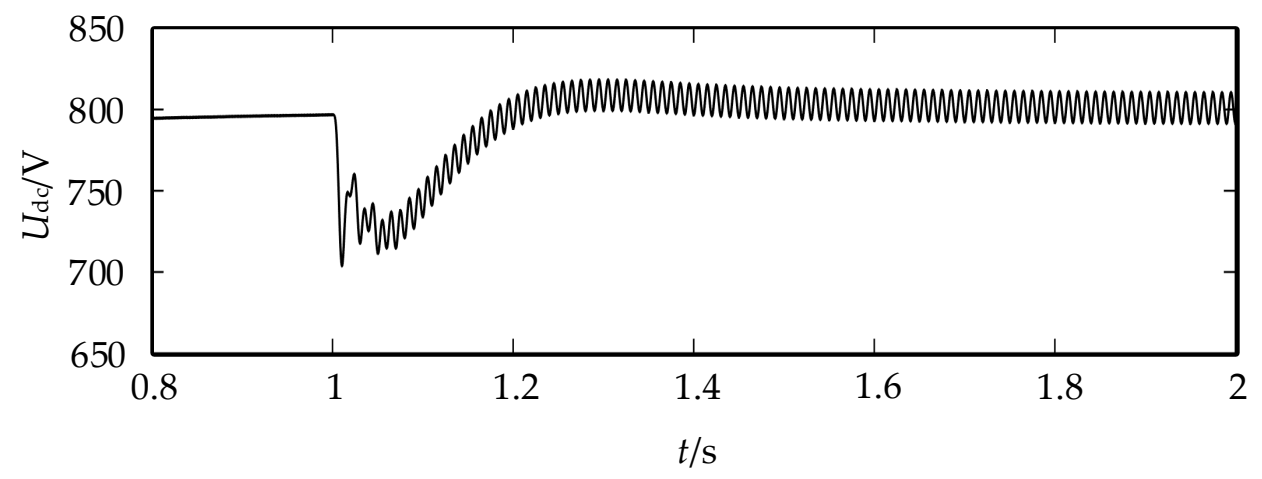

Figure 11. DC voltage with a PI current inner loop.

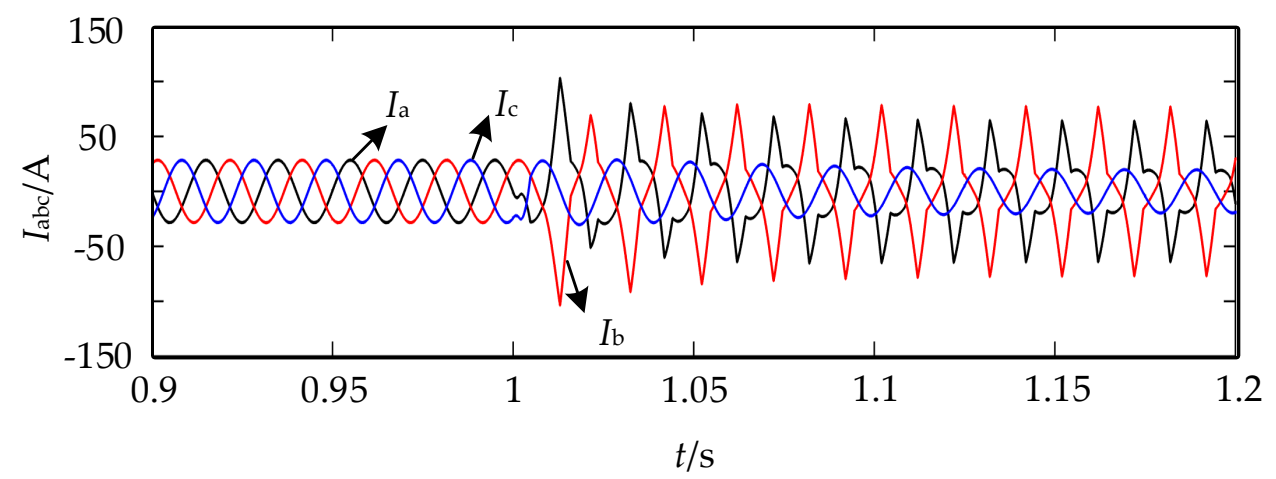

Figure 12. Three-phase currents with a current hysteresis loop.

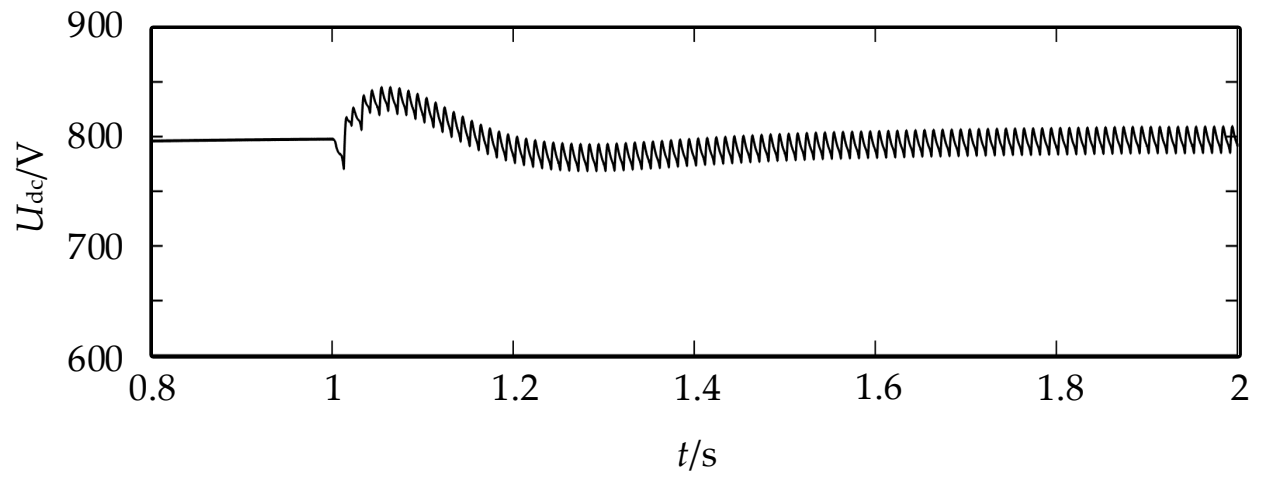

Figure 13. DC voltage with a current hysteresis loop.

Then, the simulation was rebuilt with the improved VSM strategy introduced to suppress the current negative sequence. Simulations of control strategy with the PI current inner loop and the current hysteresis loop were similar. Only one kind of simulation result is shown below. At $1 \mathrm{~s}$, phase A voltage drops from $220 \mathrm{~V}$ to $110 \mathrm{~V}$. Considering the positive sequence voltage component, the rated voltage amplitude in the reactive power control part was changed from 311 to $259 \mathrm{~V}$. Figure 14 shows the three-phase current. Without negative sequences, three-phase current on the AC side was balanced. There were double-frequency ripples on the DC bus, as shown in Figure 15. With $\pm 2.5 \mathrm{~V}$ ripples on the DC bus, the three-phase currents were balanced.

Another simulation was rebuilt with the improved VSM strategy introduced to suppress the DC voltage ripples. At $1 \mathrm{~s}$, phase A voltage dropped to $110 \mathrm{~V}$. Figure 16 shows the three-phase current. After a short transient process, the current tended to stability. The DC bus voltage dropped to $720 \mathrm{~V}$ at $1 \mathrm{~s}$, and then rose to $800 \mathrm{~V}$, and the ripples were suppressed to $\pm 1 \mathrm{~V}$, which is shown in Figure 17. 


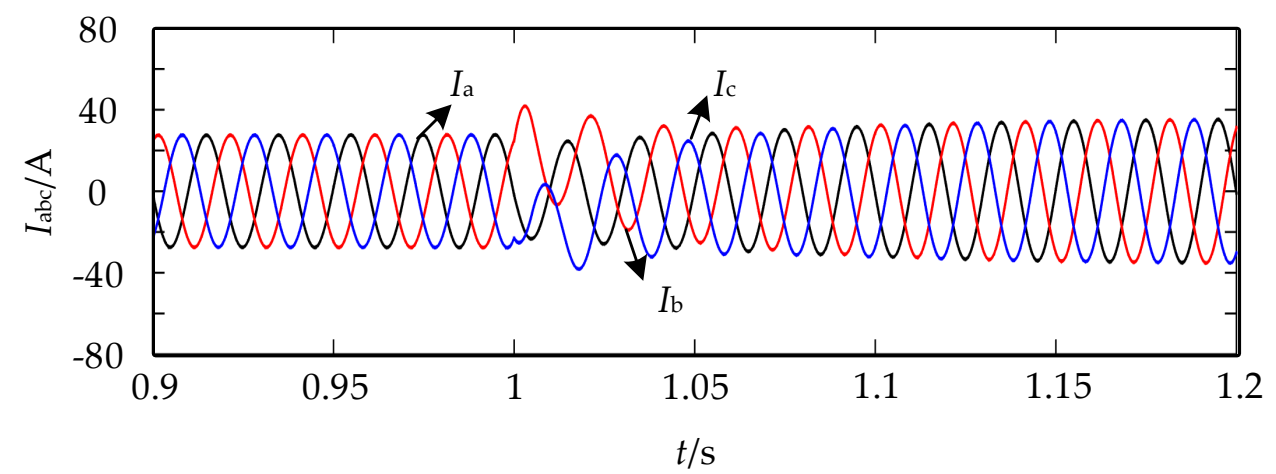

Figure 14. Three-phase current with no negative sequence.

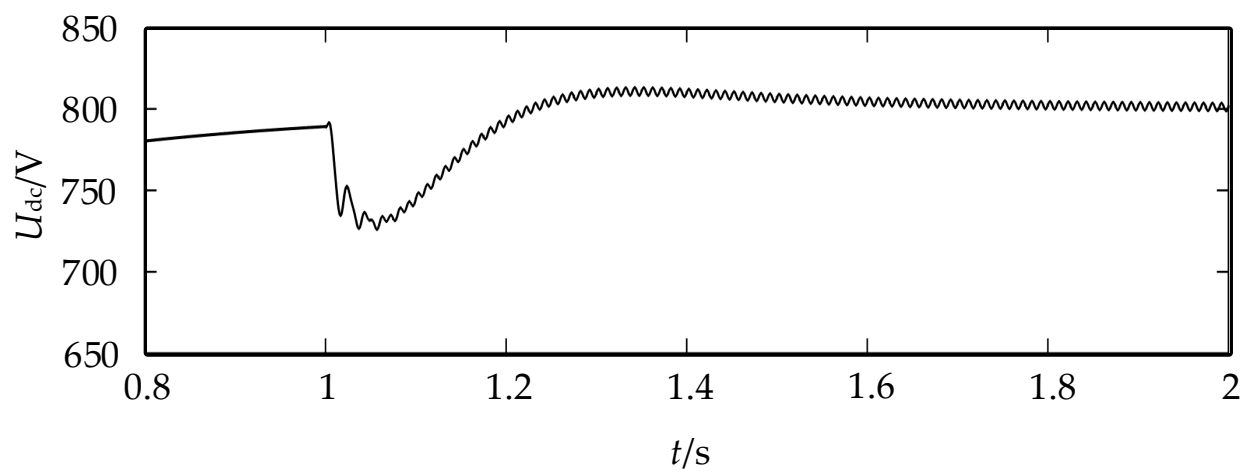

Figure 15. DC bus voltage with no current negative sequence.

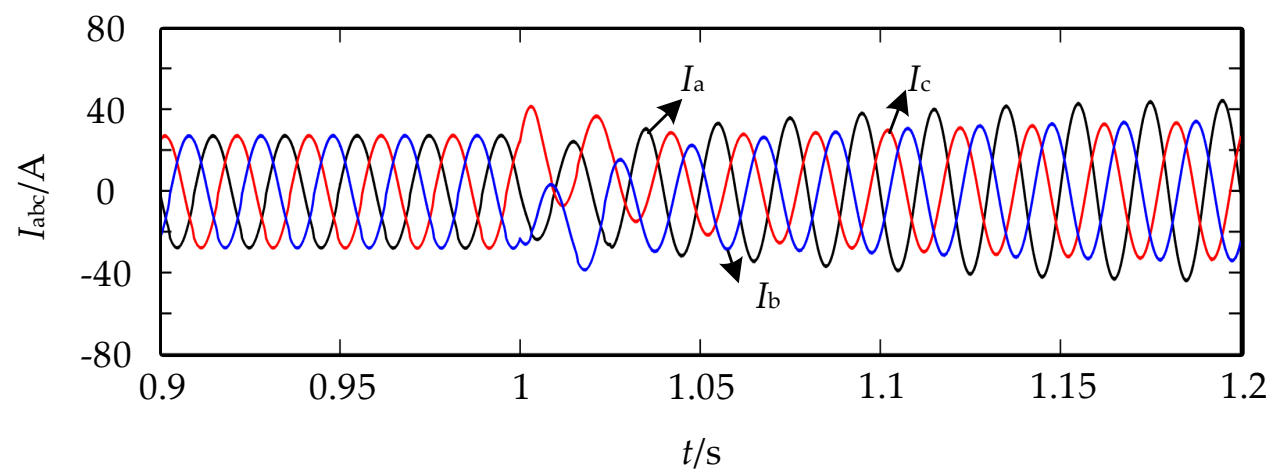

Figure 16. Three-phase current with no DC voltage ripples.

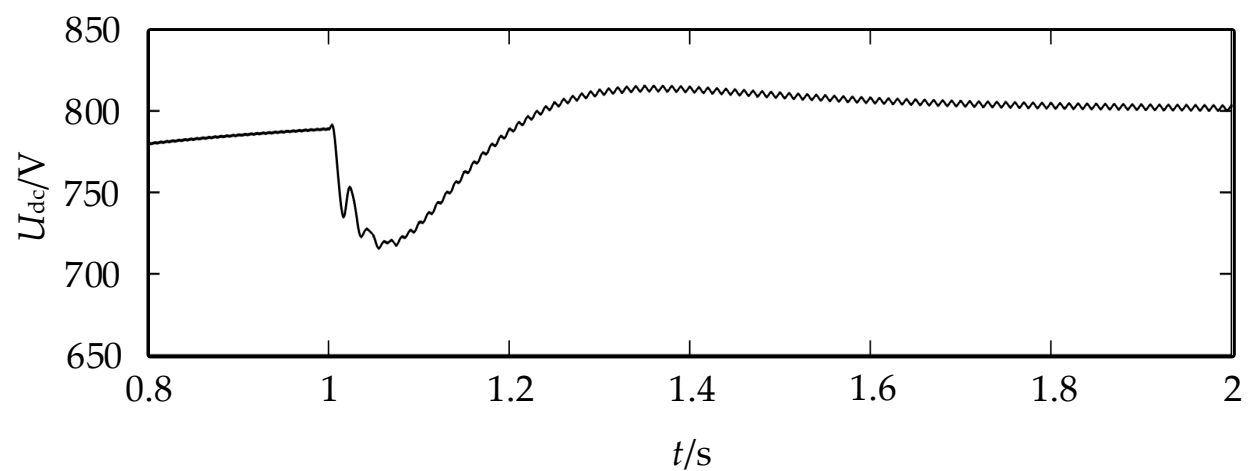

Figure 17. DC bus voltage with no ripples. 


\section{Experiment}

A three-phase converter rectifier based on the VSM control strategy was designed to verify the validity of the theoretical analysis and research. dSPACE-1103 was used in the control system for the rectifier. ASPACE is a real-time development and test platform based on MATLAB developed by German dSPACE company. It can realize a control prototype and apply the control strategy into the hardware circuit [24].

The scheme of the experiment is shown in Figure 18. The experiment parameters are shown in Table 2. The effective value of line voltage at the grid side $E_{r m s}$ was $50 \mathrm{~V}$. The DC side voltage $U_{d c}$ was $160 \mathrm{~V}$. DC side load resistance $R_{d c}$ was $100 \Omega$. The DC capacitor $C_{d c}$ was $2200 \mu \mathrm{F}$.

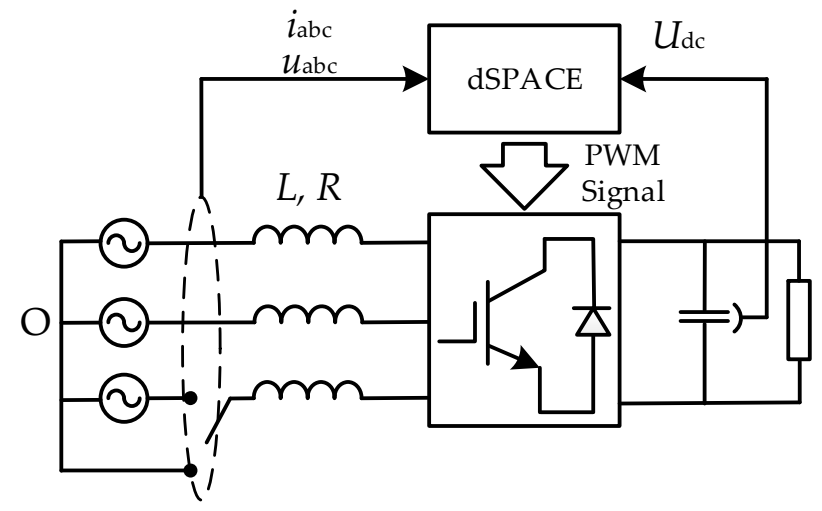

Figure 18. The scheme of the experiment.

Table 2. Experiment parameters.

\begin{tabular}{cccc}
\hline Parameter & Value & Parameter & Value \\
\hline$J /\left(\mathrm{kg} \cdot \mathrm{m}^{2}\right)$ & 0.00254 & $Q_{r e f} /$ Var & 0 \\
$D$ & 0.3 & $E_{r m s} / \mathrm{V}$ & 50 \\
$\omega_{0} /(\mathrm{rad} / \mathrm{s})$ & $100 \cdot \pi$ & $U_{d c r e f} / \mathrm{V}$ & 160 \\
$k_{v}$ & 0.01 & $R / \Omega$ & 0.3 \\
$k_{q}$ & 0.0006 & $L / \mathrm{mH}$ & 1 \\
\hline
\end{tabular}

The experiment waveform of VSM under normal conditions is shown in Figure 19. Phase A voltage and current and DC voltage are measured. The VSM was able to operate stably when the power factor was 1.

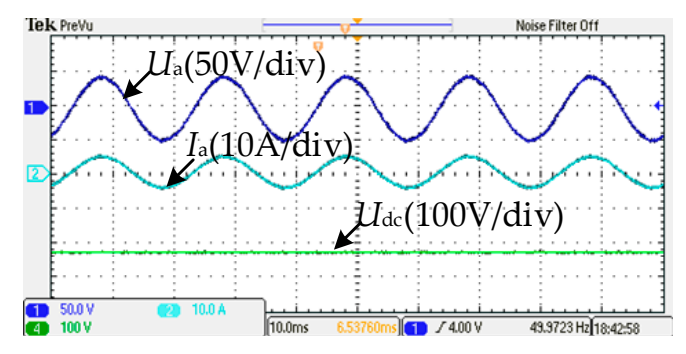

Figure 19. Voltage, current, and DC voltage under normal conditions.

In order to simulate the three-phase unbalanced conditions, phase $C$ voltage was cut off and the voltage was set to 0 . Figure 20 shows the three-phase grid voltage and DC bus voltage with the improved VSM control strategy to suppress the current negative sequence. The ripples on the DC bus was around $\pm 2 \mathrm{~V}$. Figure 21 shows the three-phase current. There were ripples on the DC bus and no negative sequence current. 


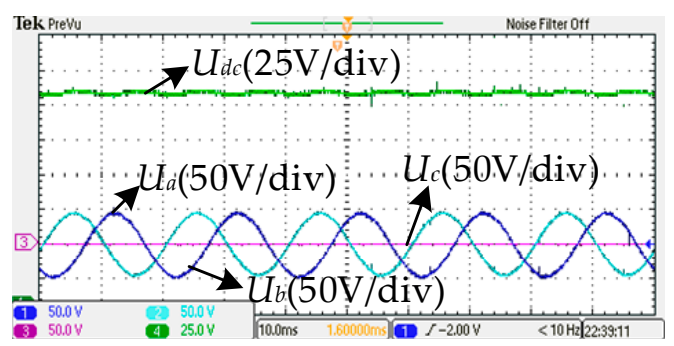

Figure 20. Three-phase grid voltage and DC bus voltage with no current negative sequence on AC side.

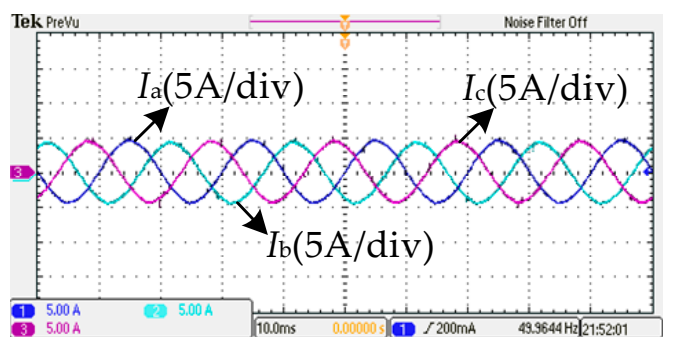

Figure 21. Three-phase current with no negative sequence.

Figure 22 shows the three-phase grid voltage and DC voltage with the improved VSM control strategy to suppress the DC voltage ripples. The ripples on the DC bus were around $\pm 0.5 \mathrm{~V}$. Figure 23 shows the three-phase current. Although the three-phase current was unbalanced, the ripples on the DC bus are suppressed.

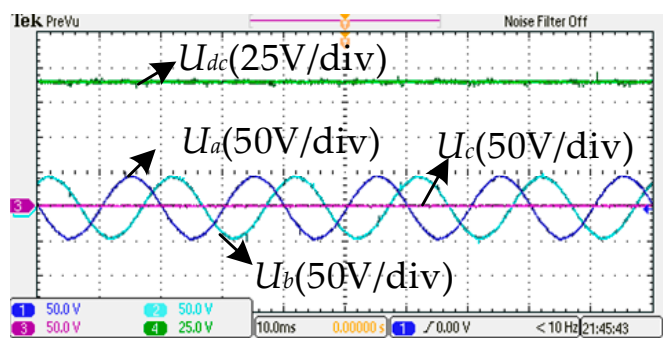

Figure 22. Three-phase grid voltage and DC voltage with no DC voltage ripples.

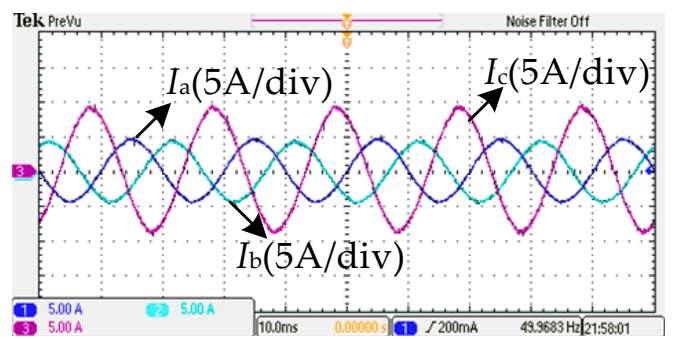

Figure 23. Three-phase current with no DC voltage ripples.

\section{Conclusions}

Compared with the traditional control strategy, VSM has more friendly interactions with the power grid. Studies on VSMs usually focus on the ideal operation. In reality, due to faults, load imbalances, and other reasons, the grid voltage may be unbalanced. This paper proposes a comprehensive VSM control strategy under unbalanced conditions. The findings of the paper can be concluded as:

(1) According to the analysis of the unbalanced grid, there are double-frequency ripples in the active and reactive power transmission, which cause the three-phase current imbalance and DC voltage fluctuation. 
(2) The complex coefficient filter is used in the positive and negative sequence separation, which greatly reduces the complexity of the system. The model and control are more efficient.

(3) The negative sequence current is suppressed by positive and negative sequence separation. Only the positive sequence network is taken into calculation. Besides that, a virtual impedance is introduced in the paper based on the principle of constant active power, and the ripples on the DC bus are suppressed. The control strategy can also be applied in an inverter. Only the DC voltage control needed to be replaced by the output active power control.

(4) The simulation and experimental results verify the correctness and validity of the proposed control strategy. However, the voltage-unbalanced operation of VSMs in parallel still needs to be further studied.

Author Contributions: Conceptualization, H.M. and J.Z.; Methodology, F.M.; Data curation, Y.Y. and H.C.; Writing, H.M.; Supervision, J.Z.

Conflicts of Interest: The authors declare no conflict of interest

\section{References}

1. Carrasco, J.M.; Garcia Franquelo, L.; Bialasiewicz, J.T.; Galván, E.; Portillo Guisado, R.C.; Martín Prats, M.D.; León, J.I.; Moreno-Alfonso, N. Power-Electronic Systems for the Grid Integration of Renewable Energy Sources: A Survey. IEEE Trans. Ind. Electron. 2006, 53, 1002-1016. [CrossRef]

2. Papadaskalopoulos, D.; Pudjianto, D.; Strbac, G. Decentralized Coordination of Microgrids With Flexible Demand and Energy Storage. IEEE Trans. Sustain. Energy 2014, 5, 1406-1414. [CrossRef]

3. Boroyevich, D.; Cvetković, I.; Dong, D.; Burgos, R.; Wang, F.; Lee, F. Future electronic power distribution systems a contemplative view. In Proceedings of the 2010 12th International Conference on Optimization of Electrical and Electronic Equipment, Basov, Romania, 20-22 May 2010; pp. 1369-1380.

4. Zhao, Z.; Yang, P.; Guerrero, J.M.; Xu, Z.; Green, T.C. Multiple-Time-Scales Hierarchical Frequency Stability Control Strategy of Medium-Voltage Isolated Microgrid. IEEE Trans. Power Electron. 2016, 31, 5974-5991. [CrossRef]

5. Jadhav, G.N.; Changan, D.D. Modelling of inverter for stability analysis of microgrid. In Proceedings of the 2016 IEEE 7th Power India International Conference (PIICON), Bikaner, India, 25-27 November 2016; pp. 1-6.

6. Li, D.; Zhu, Q.; Lin, S.; Bian, X.Y. A Self-Adaptive Inertia and Damping Combination Control of VSG to Support Frequency Stability. IEEE Trans. Energy Convers. 2017, 32, 397-398. [CrossRef]

7. Zhong, Q.; Nguyen, P.; Ma, Z.; Sheng, W. Self-Synchronized Synchronverters: Inverters Without a Dedicated Synchronization Unit. IEEE Trans. Power Electron. 2014, 29, 617-630. [CrossRef]

8. Nguyen, C.K.; Nguyen, T.T.; Yoo, H.J.; Kim, H.M. Improving Transient Response of Power Converter in a Stand-Alone Microgrid Using Virtual Synchronous Generator. Energies 2017, 11, 27. [CrossRef]

9. Edris, A.A. Proposed terms and definitions for flexible AC transmission system (FACTS). IEEE Trans. Power Deliv. 1997, 12, 1848-1853.

10. Beck, H.; Hesse, R. Virtual synchronous machine. In Proceedings of the 2007 9th International Conference on Electrical Power Quality and Utilisation, Barcelona, Spain, 9-11 October 2007; pp. 1-6.

11. Visscher, K.; de Haan, S.W.H. Virtual synchronous machines (VSG's) for frequency stabilisation in future grids with a significant share of decentralized generation. In Proceedings of the CIRED Seminar 2008: SmartGrids for Distribution, Frankfurt, Germany, 23-24 June 2008; pp. 1-4.

12. Zhong, Q.; Weiss, G. Synchronverters: Inverters That Mimic Synchronous Generators. IEEE Trans. Ind. Electron. 2011, 58, 1259-1267. [CrossRef]

13. Alatrash, H.; Mensah, A.; Mark, E.; Amarin, R.; Enslin, J. Generator emulation controls for photovoltaic inverters. In Proceedings of the 8th International Conference on Power Electronics-ECCE Asia, Jeju, South Korea, 30 May-3 June 2011; pp. 2043-2050.

14. Wang, X.; Sun, D. Multi-objective self-synchronised virtual synchronous generator in unbalanced power grid. Electron. Lett. 2018, 54, 779-781. [CrossRef] 
15. Zheng, T.; Chen, L.; Guo, Y.; Mei, S. Comprehensive control strategy of virtual synchronous generator under unbalanced voltage conditions. IET Gener. Transm. Distrib. 2018, 12, 1621-1630. [CrossRef]

16. Cheng, P.; Nian, H. Collaborative Control of DFIG System During Network Unbalance Using Reduced-Order Generalized Integrators. IEEE Trans. Energy Convers. 2015, 30, 453-464. [CrossRef]

17. Savaghebi, M.; Jalilian, A.; Vasquez, J.C.; Guerrero, J.M. Secondary Control Scheme for Voltage Unbalance Compensation in an Islanded Droop-Controlled Microgrid. IEEE Trans. Smart Grid 2012, 3, 797-807. [CrossRef]

18. Zhong, Q.; Konstantopoulos, G.C.; Ren, B.; Krstic, M. Improved Synchronverters with Bounded Frequency and Voltage for Smart Grid Integration. IEEE Trans. Smart Grid 2018, 9, 786-796. [CrossRef]

19. Liu, J.; Miura, Y.; Ise, T. Comparison of Dynamic Characteristics Between Virtual Synchronous Generator and Droop Control in Inverter-Based Distributed Generators. IEEE Trans. Power Electron. 2016, 31, 3600-3611. [CrossRef]

20. Natarajan, V.; Weiss, G. Synchronverters With Better Stability Due to Virtual Inductors, Virtual Capacitors, and Anti-Windup. IEEE Trans. Ind. Electron. 2017, 64, 5994-6004. [CrossRef]

21. Shintai, T.; Miura, Y.; Ise, T. Oscillation Damping of a Distributed Generator Using a Virtual Synchronous Generator. IEEE Trans. Power Deliv. 2014, 29, 668-676. [CrossRef]

22. Chen, X.; Zhang, C.; Huang, Q.; Meng, J. Study on a novel control strategy of three-phase inverter under unbalanced load. In Proceedings of the 2nd IET Renewable Power Generation Conference (RPG 2013), Beijing, China, 9-11 September 2013; pp. 1-4.

23. Guo, X.; Wu, W.; Chen, Z. Multiple-Complex Coefficient-Filter-Based Phase-Locked Loop and Synchronization Technique for Three-Phase Grid-Interfaced Converters in Distributed Utility Networks. IEEE Trans. Ind. Electron. 2011, 58, 1194-1204. [CrossRef]

24. Dzung, P.Q.; Bao, A.N.; le Minh, P.; le Dinh, K.; Lee, H.H. The implementation of direct virtual torque control and direct power control for DFIG in wind energy system using DSpace 1103. In Proceedings of the 2011 IEEE Ninth International Conference on Power Electronics and Drive Systems, Singapore, 5-8 December 2011; pp. 884-888.

(C) 2019 by the authors. Licensee MDPI, Basel, Switzerland. This article is an open access article distributed under the terms and conditions of the Creative Commons Attribution (CC BY) license (http:/ / creativecommons.org/licenses/by/4.0/). 